NATURAL DISASTERS AND THEORY OF MIND

\title{
Preventing the Detrimental Effect of Posttraumatic Stress in Young Children: The Role of Theory of Mind in the Aftermath of a Natural Disaster
}

\begin{abstract}
We conducted a field study to test whether parents' negative reactions to a natural disaster affected children's reactions, together with the factors buffering this negative influence. Specifically, we examined whether parents' posttraumatic stress symptoms following an earthquake were associated with children's posttraumatic symptoms and their use of negative coping strategies. Theory of Mind (ToM) was tested as the factor allowing children to reduce the detrimental effects of posttraumatic stress symptoms on negative coping. Hypotheses were tested in a sample of elementary school children and their parents in the aftermath of the earthquakes that struck Northern Italy in 2012. Results revealed that mothers' (but not fathers') posttraumatic stress symptoms were positively associated with children's posttraumatic stress symptoms, which acted as mediator on the use of negative coping strategies by children, but only among children with low ToM abilities. We discuss the theoretical and practical implications of findings.
\end{abstract}

Keywords: Theory of Mind; coping strategies; earthquake; children; posttraumatic stress disorder; natural disasters. 


\section{NATURAL DISASTERS AND THEORY OF MIND}

There is a consistent literature showing that catastrophic events, such as natural disasters, have both short- and long-term negative psychological, emotional, and behavioral consequences on individuals (Neria, Nandi, \& Galea, 2008). These adverse effects are especially strong among children and adolescents, who may be less prepared to face uncontrollable events (Furr, Corner, Edmunds, \& Kendall, 2010) and who could be especially sensitive to contextual influences, such as their parents' reaction to the stressful event (Lambert, Holzer, \& Hasbun, 2014). One consequence that may be especially detrimental is the use of maladaptive coping strategies, which would prevent an effective processing of the event, implying a reduced ability to cope with stress (Bolger, 1990).

The aim of this study is to examine the individual and contextual factors driving the use of maladaptive coping strategies among children in the aftermath of a natural disaster, together with protective factors which prevent their use. Our focus is on the stress experienced by parents and children after the disaster, and in particular on posttraumatic stress symptoms, which may be key to determine maladaptive coping. Posttraumatic stress symptoms include intrusive memories, avoidance, hyperarousal, and numbing, all factors that can be sufficient to warrant a diagnosis of posttraumatic stress disorder (American Psychiatric Association, 2000). Posttraumatic stress disorder can severely impair individuals' and, especially, children's psychological functioning (Furr et al., 2010). In particular, we test whether parents' posttraumatic stress symptoms predict children's posttraumatic stress symptoms, and whether stronger children's posttraumatic stress symptoms are in turn associated with a greater use of maladaptive coping strategies. Crucially, we test "Theory of Mind" (ToM; Premack \& Woodruff, 1978) as the factor which buffers the effects of children's posttraumatic stress 


\section{NATURAL DISASTERS AND THEORY OF MIND}

symptoms on the use of maladaptive coping to face the event. These hypotheses are tested with a large sample of children and parents exposed to the earthquakes that struck Northern Italy in 2012. To our knowledge, this is the first study that investigates ToM as a protective factor helping children to dampen the negative effects of parental stress and, as a consequence, preventing children to adopt maladaptive coping strategies in the aftermath of a natural disaster.

\section{Posttraumatic stress and children's use of maladaptive coping strategies}

We can define coping as the thoughts and behaviors used by individuals to manage internal and external demands of situations which are appraised as stressful (Folkman \& Moskowitz, 2004). Coping is a complex multidimensional process which is dependent on the person-environment relationship and which is sensitive to the demands and resources present in the environment, to personality factors, and to the appraisal of the individual's available resources (Folkman \& Lazarus, 1991).

Although developing coping abilities is fundamental in order to recover from a traumatic event, not all coping reactions are adaptive. Individuals may use qualitatively different types of coping strategies, which are likely to have differential effects on psychological functioning (Schaefer \& Moos, 1998). For instance, people could adopt maladaptive coping strategies that consist of asocial, antisocial or avoidant behaviors that are not focused on the stressor itself. Spirito, Stark, and Williams (1988) identified "negative strategies," including hostile reactions, escapist fantasies, self-blame and wishful thinking. These strategies prevent an effective cognitive and emotional processing of the event, with the result that individuals are less able to deal with stress (Bolger, 1990). Thus, it is important to understand the factors driving the use of these strategies, and the factors which prevent their adoption. 


\section{NATURAL DISASTERS AND THEORY OF MIND}

There are several factors which contribute to shape the negative consequences of natural disasters on children and which make the recovery from the stressful situation especially unlikely (Terranova, Boxer \& Morris, 2009; Vezzali, Cadamuro, Versari, Giovannini, \& Trifiletti, in press). The most relevant include degree of exposure, individual characteristics, and situational factors.

Concerning degree of exposure, there is consistent evidence showing that survivors' stress in the aftermath of a natural disaster is higher the more they have been exposed to the traumatic event (Lonigan, Shannon, Finch, \& Daugherty, 1991).

With respect to individual characteristics, there are several factors which may impact on children's responses. For instance, the impact of the traumatic event relies heavily on pre-existing emotional and behavioral difficulties (Terranova et al., 2009) and demographic factors such as age (if traumatic events are experienced before the age of 11, posttraumatic stress disorder is three times more likely to occur; Davis \& Siegel, 2000) and gender (consequences are generally more severe among females; Furr et al., 2010). An especially relevant factor is the stress resulting from the traumatic experience. Research has shown that posttraumatic stress symptoms following a disaster have several detrimental consequences among children such as possible delays of developmental processes (Gabrielli, Gill, Koester, \& Borntrager, 2014). For this reason, we consider children's posttraumatic stress symptoms as a key variable in our study. In particular, we test its effects on their use of maladaptive coping strategies following a traumatic event. To the best of our knowledge, we are not aware of any study examining this consequence of posttraumatic stress in a sample of children exposed to a natural disaster. Based on literature reviewed showing detrimental effects of posttraumatic stress among children, we predict that children's posttraumatic stress symptoms will be 


\section{NATURAL DISASTERS AND THEORY OF MIND}

positively related to their use of negative coping. This finding would be highly relevant at both theoretical as well as practical level, by showing that posttraumatic stress represents an obstacle for facing the trauma, in the sense that it possibly reduces the likelihood of recovery, also in the long-term.

There are various situational factors that may impact on children's experience and recovery. For instance, social support from peers has been shown to act in the sense of preventing cognitive disruption among young children following a disaster (Cadamuro, Versari, Vezzali, Giovannini, \& Trifiletti, 2015). A crucial role is played by parents. Caregivers can help children appraise and understand their emotions and events, provide support, disclose their perspective, and represent a guide and a role model for the use of coping (Gil-Rivas, Silver, Holman, McIntosh, \& Poulin, 2007). In this respect, one situational factor that should be considered with special attention is represented by family members' reactions to the event and, in particular, by posttraumatic stress symptoms exhibited by parents (Li, Huang, Tan, Liu, Zhou, Yang, 2010). Parents with posttraumatic stress disorder may have difficulties in assisting their children to develop effective coping strategies in the aftermath of natural disasters (Prinstein, La Greca, Vernberg, \& Silverman, 1996). Of particular note are studies showing that the family's reaction to the stressful event are better predictors of posttraumatic stress symptoms in children than the children's own exposure level (Garfin et al., 2014). In this regard, Lambert and colleagues (2014) conducted a metaanalysis considering 42 studies, and found that correlations between parents' posttraumatic stress symptoms and children's distress were as strong for parent-child dyads, where only parents had been traumatized, as they were for parent-child dyads where both parents and children had been traumatized. In other words, children's stress 


\section{NATURAL DISASTERS AND THEORY OF MIND}

strongly depends on parents' stress following exposure to the event. Indeed, the fact that correlations between parents' and children's distress where only the parent had been traumatized were not different from those where both parents and children had been traumatized speaks to the importance of considering parents' stressful reactions as predictors of children's stress. For this reason, we decided to assess both mothers' and fathers' posttraumatic stress symptoms following the traumatic event and test their association with children's posttraumatic stress symptoms.

However, to our knowledge, no study to date has merged this evidence, by showing that parental posttraumatic stress symptoms lead children to develop maladaptive coping strategies by increasing their posttraumatic stress symptoms level. In this study, we aim to provide this evidence, by examining the indirect effect of fathers' and mothers' posttraumatic stress symptoms on children's use of maladaptive coping strategies via children's posttraumatic stress symptoms.

\section{ToM as an antidote to posttraumatic stress symptoms}

An important aim of this article is to test ToM (Premack \& Woodruff, 1978) as the factor which buffers the effect of posttraumatic stress symptoms on children's use of negative coping strategies. ToM refers to the ability to attribute mental states (e.g., beliefs, desires, intentions and emotions) to others and to use these attributions for predicting and explaining their and one's own behavior (Baron-Cohen, 1995). ToM is crucial to decode and understand social cues and hence for the development of adaptive social behavior (Hughes \& Leekam, 2004). Various studies have demonstrated that ToM is a protective factor for individuals' well-being. For instance, persons who mentalize in the face of trauma are less vulnerable to psychiatric disorders (Allen, Fonagy, \& Bateman, 2008), are less likely to relive traumatic experiences (Zamir \& 


\section{NATURAL DISASTERS AND THEORY OF MIND}

Lavee, 2014), and reveal a more efficient psychological functioning (Mazza et al., 2012). Individuals with high ToM abilities are better equipped to interpret, anticipate, and influence others' behavior. They have better interpersonal relationships and more opportunities for acquiring social support and, as a consequence, they are psychologically resilient (Sang, Xi, Zuo, \& Wu, 2011) and cope more positively with stress (Fonagy, Gergely, Jurist, \& Target, 2002).

Hughes and Ensor (2007) have shown how adverse effects of harsh parenting on behavioral problems (e.g., hyperactivity) are attenuated for children with good ToM skills. However, no study has yet investigated the role of ToM as a protective factor helping children to dampen the negative effects of parents' and children's stress and, as a consequence, preventing children to adopt negative coping strategies facing natural disasters. Our hypothesis is that children's posttraumatic stress symptoms, stemming from their parents' posttraumatic stress symptoms, will predict the use of negative coping strategies only among children with low ToM abilities. This hypothesis is consistent with literature reviewed above, showing that ToM is a protective factor in the face of trauma. Indeed, children with high ToM abilities should be better able to think about the event, to reason about its meaning and to find possible explanations about mental states driving their reactions to it. Thus, they should be better equipped to make sense of the traumatic event and to respond to it more adaptively.

The model proposed, if verified, would bring together indications from separate studies showing on one side that parents' stressful experiences may influence children's experience of stress (e.g., Lambert et al., 2014), that children's stressful experiences have detrimental effects on their responses (e.g., Gabrielli et al., 2014), and that ToM may have a protective function (e.g., Hughes \& Ensor, 2007). Moreover, it would 


\section{NATURAL DISASTERS AND THEORY OF MIND}

extend previous evidence, by testing for the first time the effect of children's posttraumatic stress on negative coping and by examining whether ToM buffers this effect. It would also have important theoretical as well as practical implications because it would provide in a single test evidence for the predictors and consequences of children's posttraumatic stress, as well as the factors dampening these consequences, in a particularly sensitive sample as are children exposed to an earthquake.

\section{The present research}

The study was conducted in the aftermath of the earthquakes that occurred in Northern Italy in May 2012, when two earthquakes measuring respectively 5.9 and 5.8 points on the Richter scale struck the Emilia-Romagna Region. Consequences were severe: 27 people died, more than 300 individuals were injured, and about 40,000 people were left homeless. Participants were elementary school children and their parents living in areas deeply affected by the earthquakes.

Based on the theoretical rational presented above, we predict that parents' posttraumatic stress symptoms will be positively associated with children's posttraumatic stress symptoms. Given evidence showing that maternal stress has a stronger influence on children's posttraumatic stress symptoms compared with paternal stress (Spell et al., 2008), we predict that mothers', compared with fathers' posttraumatic stress symptoms, will have stronger effects on children's posttraumatic stress symptoms. Moreover, we expect that children's posttraumatic stress symptoms, stemming from mothers' posttraumatic stress symptoms, will foster the use of negative coping strategies only when children lack sufficient ToM abilities (i.e., when ToM abilities are low). In other words, we consider both moderator and mediator variables by combining them in a single theoretical model (for the distinction between mediators and 


\section{NATURAL DISASTERS AND THEORY OF MIND}

moderators, see Frazier, Tix, \& Barron, 2004), in order to explain when and why parents' posttraumatic stress symptoms will affect children's use of negative coping strategies. Specifically, we expect a moderated mediation effect (Preacher, Rucker, \& Hayes, 2007), such that the positive relation between mothers' and children's use of negative coping strategies, via children's posttraumatic stress symptoms, should be significant only among children with lower ToM abilities. The hypothesized model is represented in Figure 1. As can be noted, thus, children's posttraumatic stress symptoms will be tested as a mediator; children's TOM abilities are tested as a moderator.

Figure 1

\section{Method}

\section{Participants and Procedure}

The criterion for being included in the study was that children and both their parents had responded to all items used for the present study. The total sample was composed by 441 participants. Specifically, participants were 147 first- and secondgrade elementary school children (77 males, 70 females) from five elementary schools in the province of Modena, together with their parents $(N=294)$. Children's mean age was 6.83 years $(S D=0.57)$; mean age was 6.34 years $(S D=0.33)$ in first-grade and 7.31 years $(S D=0.28)$ in second-grade. Mean age of parents was 38.94 years $(S D=$ 5.38). The schools were selected by identifying areas heavily struck by the earthquake and asking for the schools' permission to investigate how children responded to the 


\section{NATURAL DISASTERS AND THEORY OF MIND}

disaster (between 5 and 12 kilometers from the epicenter). Prior to conducting the study, we secured the consent of the children's parents, teachers, and school heads.

Researchers collecting data were students enrolled in educational academic courses at a Northern Italian university. All students-researchers were accurately trained by the first three authors of the present article. The research was presented as a study on the consequences of the earthquake. Anonymity and confidentiality of responses was ensured.

The study was conducted approximately six months after the devastating earthquakes of May 2012, but only a short time after the earthquakes ended. The questionnaires were administered at the beginning of the new school year, when the acute phase of stress had presumably already ended. This choice gave us the possibility to examine responses after the traumatic event, when participants' responses were likely to be more stable. Children were individually interviewed during classes by researchers. Children were also asked to deliver two questionnaires to their parents, one to their father and one to their mother. Parents, who had been preliminary informed of the research and who had given their permissions for their children for taking part in it, returned the questionnaire in approximately one week.

We then conducted a series of encounters aimed at explaining goals and results of the research in order to provide full debriefing.

\section{Instruments}

Posttraumatic Stress Symptoms. Posttraumatic stress symptoms were assessed with the Impact of Event Scale (IES; Horowitz, Wilner, \& Alvarez, 1979), one of the most popular trauma-specific questionnaire (Sundin \& Horowitz, 2002). This instrument has been used with a variety of adult, child, and adolescent populations, 


\section{NATURAL DISASTERS AND THEORY OF MIND}

including victims of natural disaster (e.g., Green et al., 1994). The instrument consists of 15 items assessing distress produced by a specific traumatic event. For the item translation we referred to the Italian validation of the scale by Pietrantonio, De Gennaro, Di Paolo, and Solano (2003). Respondents were asked to rate the frequency of symptoms in the past 7 days on a 4 -point scale $(0=$ not at all; $1=$ rarely; $2=$ sometimes; $3=$ often). In line with Horowitz et al.'s (1979) indications, before being summed, scores were transformed, by attributing 0 to participants responding "not at all," 1 to participants responding "rarely," 3 to participants responding "sometimes," 5 to participants responding "often." The total score ranges from 0 to 75 , with scores from 0 to 8 indicating no meaningful impact of the event, scores from 9 to 25 indicating that the event may have had an impact, scores from 26 to 43 indicating that the event had a powerful impact, and scores from 44 to 75 indicating that the event had a severe impact, potentially altering the individual's cognitive functioning. Alpha was .59 for children, .82 for mothers, .87 for fathers.

ToM abilities. First-graders were administered two first-order false belief tasks: the "Sally and Anne" (Baron-Cohen, Leslie, \& Frith, 1985) and the "Smarties" tests (Hogrefe, Wimmer, \& Perner, 1986). Second-graders were administered two secondorder false belief tasks: the "Birthday Puppy" (Sullivan, Zaitchik, \& Tager-Flusberg, 1994) and the "John and Mary" tests (Perner \& Wimmer, 1985). These tasks have been shown to be reliable and valid measures of ToM (e.g., Hughes et al., 2000). We used first-order false belief tasks with first-graders because Italian children aged six may have not yet acquired the skills necessary to correctly answer to second order tasks (see, e.g., Hughes et al., 2014; Miller, 2013). . For the first-order tests, scores range from 0 to 3, with higher scores associated with higher mentalizing abilities. In each test children 


\section{NATURAL DISASTERS AND THEORY OF MIND}

received a total score of: 1 , if they passed both the test and the control question; 2 , if they correctly answered to the justification test question; 3 they referred to epistemic states. For the second-order tests, the final possible scores range from 0 to 6 . We assigned 3 points for the second order false belief question $(1=$ correct answer; $2=$ correct justification to the test question; $3=$ the justification answer embedded mental states) and 3 points to the correct probe questions. Scores from the two false belief tasks, for both first- and second-graders, were summed to provide one composite ToM score for each child (0-6 for first graders, 0-12 for second graders) as these tasks have been found to tap a common underlying cognitive capacity (Perner, 1991); previous studies have found performances on these specific tasks to be strongly associated among children (e.g., Schacht, Hammond, Marks, Wood, \& Conroy, 2013). Moreover, considering two tasks gives us the possibility to use a multi-item measure of ToM, thus increasing the validity and predictive value of our composite measure (for a similar procedure, see, e.g., Cadamuro et al., 2015). Since the range of scores for the various tests was different, scores were transformed into $z$-points before being summed.

Negative coping. To assess negative coping, we used the Kidcope scale (Spirito et al., 1988). The Kidcope has been developed and used in a wide variety of settings and applications (see Pfefferbaum et al., 2013), including children's coping styles following a natural disaster (Vigna, Hernandez, Kelley, \& Gresham, 2010). It consists of a checklist including 2 items, assessing self-criticism and blaming others strategies. Participants were asked to indicate, for each item, whether or not they used the strategy in order to deal with the earthquake. Each strategy checked by the child received the score of 1 ; in case the child did not use the strategy, the score was 0.

\section{Results}




\section{NATURAL DISASTERS AND THEORY OF MIND}

Means, standard deviations, and correlations for the various measures are presented in Table 1, in which $z$-transformed scores for the overall score of ToM abilities (computed as the sum of $z$-transformed scores of the two false belief tests) are presented. Mean scores for the false belief tests were: $M=0.82(S D=1.06)$ for the "Sally and Anne" test; $M=1.48(S D=0.94)$ for the "Smarties" test; $M=3.22(S D=$ 1.15) for the "Birthday Puppy" test; $M=3.90(S D=1.26)$ for the "John and Mary" test (scores ranged from 0 to 3 for the first two tests, from 0 to 6 for the last two tests).

As can be noted in Table 1, mothers' (but not fathers') posttraumatic stress symptoms were positively associated with children's posttraumatic stress symptoms. Zero-order correlations however did not reveal an association between children's posttraumatic stress symptoms and negative coping. However, this is not problematic for our hypotheses, since we predicted that the association between children's posttraumatic stress symptoms and negative coping would be moderated by ToM abilities.

\section{Table 1}

To test our hypotheses (see Figure 1), hierarchical regression was applied. In all regressions, school grade and gender were included as covariates. Results are presented in Table 2.

First, we tested whether mothers' and fathers' posttraumatic stress symptoms influenced their children's posttraumatic stress symptoms. As can be noted in Table 2, 


\section{NATURAL DISASTERS AND THEORY OF MIND}

in line with our hypothesis, posttraumatic stress symptoms of mothers were positively associated with those revealed by children.

In the second regression, we tested whether, controlling for mothers' and fathers' posttraumatic stress symptoms, children's posttraumatic stress symptoms would influence negative coping depending on the level of children's ToM abilities (see Table 2). In line with predictions, the expected interaction between children's posttraumatic stress symptoms and ToM abilities was significant. Fully supporting hypotheses, simple slope analysis showed that children's posttraumatic stress symptoms were positively associated with negative coping when ToM abilities were low $(-1 S D), b=.02, t=2.91$, $p<.01$; the association between children's posttraumatic stress symptoms and negative coping was nonsignificant when ToM abilities were high (+1 SD), $b=-.00, t<1$.

In order to test whether the indirect effect of mothers' posttraumatic stress symptoms (independent variable) on children's greater use of negative coping strategies (dependent variable) via children's posttraumatic stress symptoms (mediator) depending on children's ToM abilities (moderator) was significant, bootstrapping analyses $(1,000$ resamples) were conducted by using the SPSS macros provided by Hayes (2012, Model 14). With bootstrapping procedures, a $95 \%$ confidence interval $(\mathrm{CI})$ is computed around the path from the predictor to the criterion variable through the mediator. An indirect effect is significant when 0 is excluded from the $95 \%$ confidence interval. In line with expectations, results showed that the indirect effect was significant only when ToM abilities were low (CI comprised between .001 and .012), but not when ToM abilities where high (CI comprised between -.005 and .003)..$^{1,2}$ 
Table 2

\section{Discussion}

A first relevant finding is the positive association between mothers' (but not fathers') and children's posttraumatic stress symptoms, which suggests that maternal stress is a salient risk factor for children. These findings are in line with literature showing positive associations between maternal, but not paternal, posttraumatic distress and child's post traumatic symptoms (Morris, Gabert-Quillen, \& Delahanty, 2012). It is possible that this effect arises from the role that mothers, more than fathers, play in the relationship with their children as the primary caregiver (Pleck, 1997), but it is not excluded that this association also arises, at least in part, from biological genetic factors (Yehuda \& Bierer, 2009).

Most notably, children's posttraumatic stress symptoms (stemming from mothers' posttraumatic stress symptoms) were positively associated with the use of negative coping only for children low in ToM. When a child adopts negative coping strategies, not only the use of adaptive coping strategies may be inhibited, but there is also an increased likelihood of negative outcomes (e.g., difficulties in trusting others, over-sensitivity in interpersonal interactions, reduction in assertive behavior during interactions; Heppner \& Lee, 2002). Our study suggests that children's difficulties to properly define own and others' mental states, associated with low ToM performance, lead to difficulties in identifying appropriate strategies to cope with a stressful event. Although there is a wide literature regarding the factors that shape the negative 


\section{NATURAL DISASTERS AND THEORY OF MIND}

consequences of natural disasters on children, this is the first study showing that ToM protects children from their own and parental stress, inhibiting the use of negative coping in the aftermath of a natural disaster. In this regard, an emerging literature shows the role of ToM as a key factor in dealing with stress related to traumatic experiences: children with developed ToM have additional skill sets crucial to actively seek social support and maintain positive social interactions that, in turn, increase the likelihood of being resilient (Sang et al., 2011). They are also more likely to report symptoms associated with trauma (e.g., intrusive thoughts with negative content), making more effective post-trauma interventions (Sprung, 2008).

The present study considerably extends previous literature, by considering both individual (children's posttraumatic stress) and situational factors (parents' posttraumatic stress) and their reciprocal relationships, as well as examining their detrimental effects (use of maladaptive coping by children) and factors preventing them (ToM). Our study also illuminates findings from Lambert et al. (2014), by demonstrating that negative effects of parental stress on offspring coping strategies can be mitigated by children's high ToM skills. We believe that higher ToM allows the children to be more able to think to the event and its meaning, thus making more sense of it and of the ways to face its consequences.

Finally, we acknowledge some limitations. First, results are correlational, so we cannot make claims about the causal direction of the relationships emerged. Second, we did not include a measure of well-being, which is a fundamental variable to take into consideration when examining the consequences of traumatic events. Another problematic aspect concerns the fact that children may have suffered differential exposure to the earthquake but, unfortunately, we do not have access to the information 


\section{NATURAL DISASTERS AND THEORY OF MIND}

regarding where participants lived (e.g., tent cities or home; in any case, most part of children lived at home at the time of data collection, although we do not have exact data on it), or whether they live with both parents. A further possible limitation is that we collected data after the traumatic event was ended, in order to examine stable responses following the event. Note that collecting data before would have been difficult, since schools were closed. However, future studies may consider examining the trajectories of participants' stress and coping during the acute phase (and thus, in the middle of the event), in order to better understand the evolution of symptoms (and associated responses) during time. Finally, we did not collect data on parents' coping strategies and ToM ability. Future studies should consider more carefully the role of these factors in the onset of negative coping strategies in children. 


\section{Footnotes}

1. Regression analyses were replicated controlling for the effects of school of belonging by using the cluster option in PROCESS (Hayes, 2012). Results were virtually identical.

2. We conducted additional analyses showing that school grade and gender did not moderate any of the hypothesized paths (Figure 1). 


\section{References}

Allen, J., Fonagy, P., \& Bateman, A. W. (2008). Mentalizing in clinical practice. Washington, DC: American Psychiatric Publishing.

American Psychiatric Association (2000). Diagnostic and statistical manual of mental disorders (4th ed., text revision). Washington, DC: American Psychiatric Association.

Baron-Cohen, S. (1995). Mindblindness: An essay on autism and theory of mind. London, UK: MIT Press.

Baron-Cohen, S., Leslie, A. M., \& Frith, U. (1985). Does the autistic-child have a theory of mind. Cognition, 21, 37-46. doi: 10.1016/0010-0277(85)90022-8

Bolger, N. (1990). Coping as a personality process: A prospective study. Journal of Personality and Social Psychology, 59, 525-537. doi: 10.1037/0022-3514.59.3.525

Cadamuro, A., Versari, A., Vezzali, L., Giovannini, D., \& Trifiletti, E. (2015). Cognitive performance in the aftermath of a natural disaster: The role of coping strategies, Theory of Mind and peer social support. Child \& Youth Health Care Forum, 44, 93-113. doi: 10.1007/s10566-014-9272-z

Davis, L., \& Siegel, L. (2000). Posttraumatic stress disorder in children and adolescents: A review and analysis. Clinical Child and Family Psychology Review, 3, 135-154. doi: 10.1023/A:1009564724720

Folkman, S., \& Lazarus, R. S. (1991). Coping and emotion. In A. Monat \& R. S. Lazarus (Eds.), Stress and coping: An anthology (pp. 207-227). New York, NY: Columbia University Press. 


\section{NATURAL DISASTERS AND THEORY OF MIND}

Folkman, S., \& Moskowitz, J. (2004). Coping: Pitfalls and promise. Annual Review of Psychology, 55, 745-774. doi: 10.1146/annurev.psych.55.090902.141456

Fonagy, P., Gergely, G., Jurist, E. L., Target, M. (2002). Affect regulation, mentalisation and the development of the self. New York, NY: Other Press.

Frazier, P. A., Tix, A. P., \& Barron, K. E. (2004). Testing moderator and mediator effects in counseling psychology. Journal of Counseling Psychology, 51, 115-134. doi: 10.1037/0022-0167.51.1.115

Furr, J. M., Corner, J. S., Edmunds, J. M., \& Kendall, P. C. (2010). Disasters and youth: A meta-analytic examination of posttraumatic stress. Journal of Consulting and Clinical Psychology, 78, 765-780. doi: 10.1037/a0021482

Gabrielli, J., Gill, M., Koester, L. S., \& Borntrager, C. (2014). Psychological perspectives on 'Acute on Chronic' trauma in children: Implications of the 2010 earthquake in Haiti. Children \& Society, 28, 438-450. doi: 10.1111/chso.12010

Garfin, D. R., Silver, R. C., Gil-Rivas, V., Guzman, J., Murphy, J. M., Cova, F.,... Guzman, M. P. (2014). Children's reactions to the 2010 Chilean earthquake: The role of trauma exposure, family context, and school-based mental health programming. Psychological Trauma-Theory Research Practice and Policy, 6, 563-573. doi: $10.1037 / \mathrm{a} 0036584$

Gil-Rivas, V., Silver, R. C., Holman, E. A., McIntosh, D., \& Poulin, M. (2007). Parental response and adolescent adjustment to the September 11, 2001 terrorist attacks. Journal of Traumatic Stress, 20, 1063-1068. doi: 10.1002/jts.20277

Green, B. L., Grace, M. C., Vary, M. G., Kramer, T. L., Gleser, G. C., \& Leonard, A. C. (1994). Children of disaster in the 2nd decade: A 17-year follow-up of buffalo creek 


\section{NATURAL DISASTERS AND THEORY OF MIND}

survivors. Journal of The American Academy of Child and Adolescent Psychiatry, 33, 71-79. doi: 10.1097/00004583-199401000-00011

Hayes, A. F. (2012). PROCESS: A versatile computational tool for observed variable mediation, moderation, and conditional process modeling. Retrieved from http://www.afhayes.com/public/process2012.pdf

Heppner, P. P., \& Lee, D. (2002). Problem-solving appraisal and psychological adjustment. In C. R. Snyder \& S. J. Lopez (Eds.), Handbook of positive psychology (pp. 288-298). New York, NY: Oxford University Press.

Hogrefe, G.J., Wimmer, H., \& Perner, J. (1986). Ignorance versus false belief - a developmental lag in attribution of epistemic states. Child Development, 57, 567582. doi: $10.2307 / 1130337$

Horowitz, M., Wilner, N. J., \& Alvarez, W. (1979). Impact of events scale: A measure of subjective stress. Psychosomatic Medicine, 41, 209-218.

Hughes, C., Adlam, A., Happé, F., Jackson, J., Taylor, A., \& Caspi, A. (2000). Good test-retest reliability for standard and advanced false-belief tasks across a wide range of abilities. Journal of Child Psychology and Psychiatry, 41, 483-490. doi: $10.1017 / \mathrm{S} 0021963099005533$

Hughes, C., Devine, R., Ensor, R., Koyasu, M., Misokawa, A., \& Lecce, S. (2014). Lost in translation? Comparing British, Japanese and Italian children's Theory of Mind performance. Child Development Research Manuscript. doi:10.1155/2014/893492.

Hughes, C., \& Ensor, R. (2007). Positive and protective: Effects of early theory of mind on problem behaviors in at-risk preschoolers. Journal of Child Psychology and Psychiatry, 48, 1025-1032. doi: 10.1111/j.1469-7610.2007.01806.x 


\section{NATURAL DISASTERS AND THEORY OF MIND}

Hughes, C., \& Leekam, S. (2004). What are the links between Theory of Mind and social relations? Review, reflections and new directions for studies of typical and atypical development. Social Development, 13, 590-619. doi: 10.1111/j.14679507.2004.00285.x Lambert, J. E., Holzer, J., \& Hasbun, A. (2014). Association between parents' PTSD severity and children's psychological distress: A metaanalysis. Journal of Traumatic Stress, 27, 9-17. doi: 10.1002/jts.21891

Li, X., Huang, X., Tan, H., Liu, A., Zhou, J., \& Yang, T. (2010). A study on the relationship between posttraumatic stress disorder in flood victim parents and children in Hunan. Australian and New Zealand Journal of Psychiatry, 44, 543-550.

Lonigan, C. J., Shannon, M. P., Finch, A. J., \& Daugherty, T. K. (1991). Children's reactions to a natural disaster: Symptom severity and degree of exposure. Advances in Behaviour Research \& Therapy, 13, 135-154. doi:10.1016/0146-6402(91)90002-R

Mazza, M., Giusti, L., Albanese, A., Mariano, M., Pino, M. C., \& Roncone, R. (2012). Social cognition disorders in military police officers affected by posttraumatic stress disorder after the attack of An-Nasiriya in Iraq 2006. Psychiatry Research, 198, 248252. doi: 10.1016/j.psychres.2011.11.027

Miller, S. A. (2013). Children's understanding of second-order false belief: Comparisons of content and method of assessment. Infant and Child Development, 22, 649-658. doi: 10.1002/icd.1810

Morris, A., Gabert-Quillen, C., \& Delahanty, D. (2012). The association between parent PTSD/depression symptoms and child PTSD symptoms: A meta-analysis. Journal of Pediatric Psychology, 37, 1076-1088. doi: 10.1093/jpepsy/jss091 


\section{NATURAL DISASTERS AND THEORY OF MIND}

Neria, Y., Nandi, A., \& Galea, S. (2008) Post-traumatic stress disorder following disasters: A systematic review. Psychological Medicine, 38, 467-480. doi: $10.1017 / \mathrm{S} 0033291707001353$

Perner, J. (1991). Understanding the representational mind. Cambridge, MA: MIT Press.

Perner, J., \& Wimmer, H. (1985). John thinks that Mary thinks that: Attribution of 2ndorder beliefs by 5-year-old to 10-year-old children. Journal Of Experimental Child Psychology, 39, 437-471. doi: 10.1016/0022-0965(85)90051-7

Pfefferbaum, B., Weems, C. F., Scott, B. G., Nitiema, P., Noffsinger, M. A., Pfefferbaum, R. L., \& Chakraburtty, A. (2013). Research methods in child disaster studies: A review of studies generated by the September 11, 2001, terrorist attacks; The 2004 Indian Ocean Tsunami; And Hurricane Katrina. Child \& Youth Care Forum, 42, 285-337. doi: 10.1007/s10566-013-9211-4

Pietrantonio, F., De Gennaro, L., Di Paolo, M. C., \& Solano, L. (2003). The impact of event scale - Validation of an Italian version. Journal of Psychosomatic Research, 55, 389-393. doi: 10.1016/S0022-3999(02)00638-4

Pleck, J. H. (1997). Paternal involvement: Levels, sources and consequences. In M. E. Lamb (Ed.), The role of the father in child development (3rd ed., pp. 66-103). New York, NY: Wiley.

Preacher, K. J., Rucker, D. D., \& Hayes, A. F. (2007). Addressing moderated mediation hypotheses: Theory, methods, and prescriptions. Multivariate Behavioral Research, 42, 185-227. doi: 10.1080/00273170701341316 


\section{NATURAL DISASTERS AND THEORY OF MIND}

Premack, D., \& Woodruff, G. (1978). Does the chimpanzee have a theory of mind? Behavioral and Brain Sciences, 4, 515-526. doi: $10.1017 / \mathrm{S} 0140525 \mathrm{X} 00076512$

Prinstein, M. J., LaGreca, A. M., Vernberg, E. M., \& Silverman, W. K. (1996). Children's coping assistance: How parents, teachers, and friends help children cope after a natural disaster. Journal of Clinical Child Psychology, 25, 463-475. doi: 10.1207/s15374424jccp2504_11

Sang, B., Xi, J., Zuo, Z., \& Wu, W. (2011). Theory of Mind in resilient children. Psychological Science (China), 34, 581-587.

Schacht, R., Hammond, L., Marks, M., Wood, B., \& Conroy, S. (2013). The relation between mind-mindedness in mothers with borderline personality disorder and mental state understanding in their children. Infant and Child Development, 22, 6884. doi: 10.1002/icd.1766

Schaefer, J. A., \& Moos, R. H. (1998). The context for personal growth: Life crises, individual and social resources, and coping. In R. Tedeschi, C. Park, \& L. Calhoun (Eds.), Posttraumatic growth: Positive change in the aftermath of crisis. Mahawah NJ: Erlbaum.

Spell, A. W., Kelley, M. L., Wang, J., Self-Brown, S., Davidson, K. L., Pellegrin, A., \& Baumeister, A. (2008). The moderating effects of maternal psychopathology on children's adjustment post-Hurricane Katrina. Journal of Clinical Child And Adolescent Psychology, 37, 553-563. doi: 10.1080/1.5374410802148210

Spirito, A., Stark, L., \& Williams, C. (1988). Development of a brief coping checklist for use with pediatric populations. Journal of Pediatric Psychology, 13, 555-574. doi:10.1093/jpepsy/13.4.555 


\section{NATURAL DISASTERS AND THEORY OF MIND}

Sprung, M. (2008). Unwanted intrusive thoughts and cognitive functioning in kindergarten and young elementary school-age children following Hurricane Katrina. Journal of Clinical Child and Adolescent Psychology, 37, 575-587. doi: $10.1080 / 15374410802148236$

Sullivan, K., Zaitchik, D., \& Tager-Flusberg, H. (1994). Preschoolers can attribute second order beliefs. Developmental Psychology, 30, 395-402. doi: 1037/00121649.30.3.395

Sundin, E. C., \& Horowitz, M. J. (2002). Impact of event scale: Psychometric properties. British Journal of Psychiatry, 180, 205-209. doi: 10.1192/bjp.180.3.205

Terranova, A. M., Boxer, P., \& Morris, A. S. (2009). Factors influencing the course of posttraumatic stress following a natural disaster: Children's reactions to Hurricane Katrina. Journal of Applied Developmental Psychology, 30, 344-355. doi: 10.1016/j.appdev.2008.12.017

Vezzali, L., Cadamuro, A., Versari, A., Giovannini, D., \& Trifiletti, E. (in press). Feeling like a group after a natural disaster: Common ingroup identity and relations with outgroup victims among majority and minority young children. British Journal of Social Psychology. doi: 10.1111/bjso.12091

Vigna, J. F., Hernandez, B. C., Kelley, M. L., \& Gresham, F. M. (2010). Coping behavior in hurricane-affected African American youth: Psychometric properties of the kidcope. Journal of Black Psychology, 36, 98-121. doi:

$10.1177 / 0095798408329948$

Yehuda, R., \& Bierer, L. A. (2009). The relevance of epigenetics to PTSD: Implications for the DSM-V. Journal of Traumatic Stress, 22, 427- 434. doi: 10.1002/jts.20448 
Zamir, O., \& Lavee, Y. (2014). Psychological mindedness as a protective factor against revictimization in intimate relationships. Journal of Clinical Psychology, 70, 847859. doi: 10.1002/jclp.22061, 2014 
Table 1. Means, standard deviations and correlations among variables $(N=147)$.

\begin{tabular}{|c|c|c|c|c|c|}
\hline & 1 & 2 & 3 & 4 & 5 \\
\hline $\begin{array}{l}\text { 1. Mothers' posttraumatic stress } \\
\text { symptoms }\end{array}$ & - & & & & \\
\hline $\begin{array}{l}\text { 2. Fathers' posttraumatic stress } \\
\text { symptoms }\end{array}$ & $.45 * * *$ & - & & & \\
\hline $\begin{array}{l}\text { 3. Children's posttraumatic stress } \\
\text { symptoms }\end{array}$ & $.24 * *$ & .13 & - & & \\
\hline 4. ToM abilities & -.13 & .01 & .11 & - & \\
\hline 5. Negative coping & -.05 & -.03 & .08 & .02 & - \\
\hline$M$ & 46.34 & 37.64 & 33.75 & 0.00 & 0.93 \\
\hline$S D$ & 13.53 & 16.29 & 11.83 & 1.53 & 0.87 \\
\hline
\end{tabular}

Note. Response scale ranges were: 0-75 for mothers', fathers' and children's posttraumatic stress symptoms; 0-2 for negative coping. For ToM abilities, we computed standardized scores separately for first- and second-graders; untrasformed scores, separately for school grades, are reported in the main text. $* p<.05 . * * p<.01 . * * * p<.001$. 


\section{NATURAL DISASTERS AND THEORY OF MIND}

Table 2. Hierarchical regressions testing the model proposed $(N=147)$.

\begin{tabular}{|c|c|c|c|}
\hline & \multirow{2}{*}{$\begin{array}{l}\text { Mediator variable model } \\
\text { (children's posttraumatic stress } \\
\text { symptoms) }\end{array}$} & \multicolumn{2}{|c|}{$\begin{array}{l}\text { Dependent variable model } \\
\text { (negative coping) }\end{array}$} \\
\hline & & First step & Second step \\
\hline Mothers' posttraumatic stress symptoms & $.24 * *$ & -.10 & -.10 \\
\hline Fathers' posttraumatic stress symptoms & .02 & -.00 & .01 \\
\hline School grade & $.17 *$ & $-.28 * * *$ & $-.29 * * *$ \\
\hline Gender & -.01 & -.04 & -.05 \\
\hline Children's posttraumatic stress symptoms & - & $.16^{\dagger}$ & $.16^{\dagger}$ \\
\hline ToM abilities & - & -.01 & -.01 \\
\hline Children's posttraumatic stress symptoms & - & - & $-.18 *$ \\
\hline$\times$ ToM abilities & & & \\
\hline$R^{2}$ & .09 & .09 & .12 \\
\hline$F$ & $3.44 * *$ & $2.27 *$ & $2.73 *$ \\
\hline$d f$ & $(4,142)$ & $(6,140)$ & $(7,139)$ \\
\hline Fchange & - & - & $5.11 *$ \\
\hline$d f$ & - & - & $(1,139)$ \\
\hline
\end{tabular}


NATURAL DISASTERS AND THEORY OF MIND

Figure 1. Proposed theoretical model. 
Figure 1

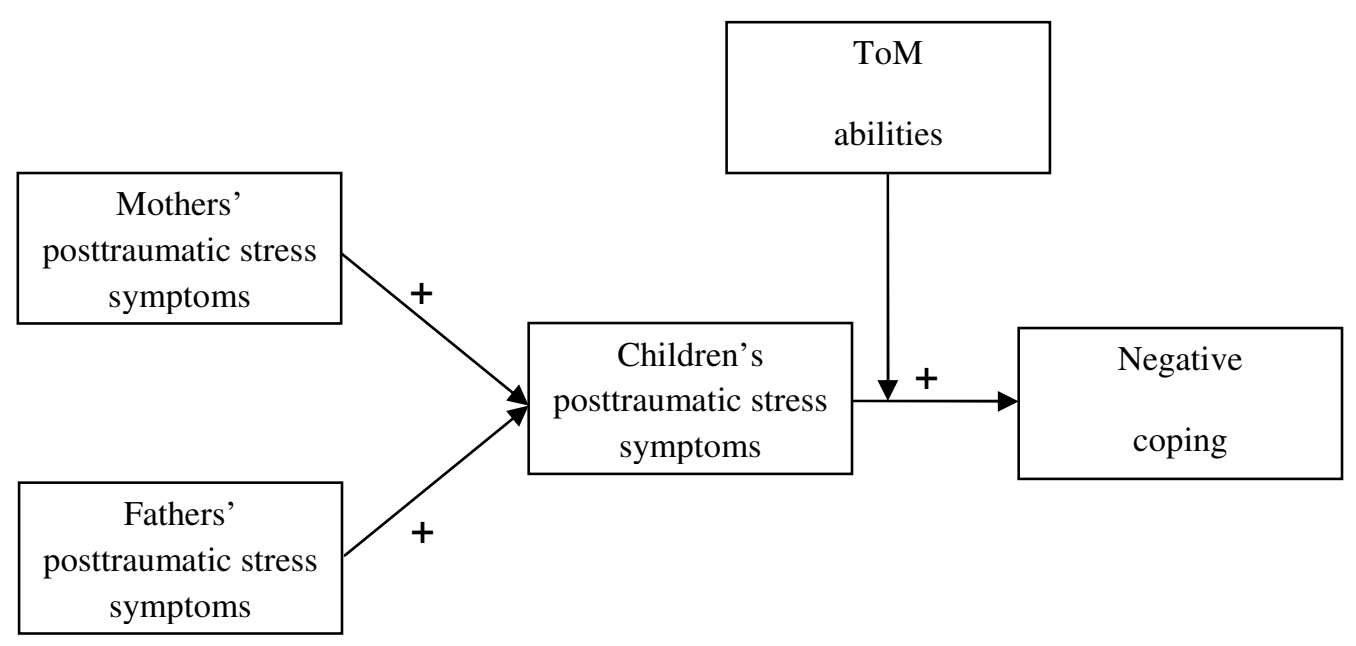

